\title{
ORIGINAL
}

\section{Recurrent autoimmune hypophysitis successfully treated with glucocorticoids plus azathioprine: a report of three cases}

\author{
Guo-Qing Yang*, Zhao-Hui Lu*, Wei-Jun Gu, Jin Du, Qing-Hua Guo, Xian-Ling Wang, Jian-Ming Ba, \\ Jing-Tao Dou, Yi-Ming Mu and Ju-Ming Lu
}

Department of Endocrinology, Chinese PLA General Hospital, Beijing, PR China

\begin{abstract}
Recurrent autoimmune hypophysitis is a rare autoimmune endocrine disease involving lymphocytic infiltration and chronic pituitary inflammation. It is even more rare than primary hypophysitis. The objective of the study was to evaluate the efficacy of glucocorticoid treatment combined with azathioprine for treating three cases of recurrent autoimmune lymphocytic hypophysitis encountered within a two-year period. The clinical features and follow-up data of these cases were analyzed, including results of treatment with glucocorticoids combined with azathioprine. All three patients were female and presented with the following clinical characteristics: case 1 was a 22-year-old with headache and diplopia; case 2 was a 70-year-old with dry mouth, polydipsia, and polyuria; case 3, a 32-year-old, with polydipsia, polyuria and menstrual disorders with headache and dizziness. Regarding recurrence, case 1 recurred 4 months after surgery and again 14 months after discontinuing prednisone; case 2 relapsed 16 months after receiving high-dose methylprednisolone pulse therapy; and case 3 recurred during the period of prednisone dose reduction. The patients were treated with glucocorticoids plus azathioprine, and positive responses were seen in all three cases. Symptoms were relieved, and MRI revealed significant reduction of lesions during follow-up. Pituitary function resumed in cases 1 and 3; permanent hypopituitarism was present in case 2. At last follow-up, MRI showed no further recurrence of disease in any patient. Treatment and responses of these patients with autoimmune hypophysitis suggest that glucocorticoid therapy combined with azothioprine is effective treatment for recurrent autoimmune hypophysitis. Endocrine and radiologic studies are an essential part of follow-up.
\end{abstract}

Key words: Glucocorticoids, Azathioprine, Autoimmune hypophysitis, Recurrence

\begin{abstract}
AUTOIMMUNE hypophysitis (AH), also termed lymphocytic hypophysitis, is a rare autoimmune endocrine disease characterized by lymphocytic infiltration of the pituitary gland and chronic pituitary inflammation [1]. Clinical manifestations of AH include pituitary dysfunction and diabetes insipidus. It affects females far more often than males, is associated with pregnancy, and may present with nausea, vomiting and hyperprolactinemia, which may cause breast milk production and menstrual disturbances in non-pregnant women $[2,3,4]$. Characteristic imaging manifestations of hypophysitis include homogenous pituitary enlarge-

Received Nov. 5, 2010; Accepted May 18, 2011 as K10E-334 Released online in J-STAGE as advance publication Jun. 10, 2011 Correspondence to: Ju-Ming Lu, Department of Endocrinology, Chinese PLA General Hospital, 28 Fu Xing Road, Beijing 100853, PR China. E-mail: endocrine301@126.com

* These two authors contributed equally to this work.

Disclosure: The authors have no conflict of interest or other disclosures to report.
\end{abstract}

ment and pituitary stalk thickening. Specifically, in lymphocytic adenohypophysitis (LAH) and lymphocytic infudibulopanhypophysitis (LIPH), the following magnetic resonance imaging (MRI) manifestations may be observed: i) intrasellar mass with homogeneous enhancement or ring-like enhancement and triangle and/or saddle diaphragm involvement or ii) diffuse and symmetrical pituitary enlargement with a blurred border; iii) tongue-like changes above the sella turcica; and iv) a delay in total enhance time (>90 sec) as observed by dynamic contrast-enhanced MRI [5]. For lymphocytic infundibuloneurohypophysitis (LINH) and LIPH the following may be observed: i) diffuse thickening of pituitary stalk (enhanced or not enhanced) and ii) the absence of strong signals in the posterior pituitary as observed in T1-weighted images [5]. Pathological examination is the main basis for diagnosis, but as an autoimmune disease, $\mathrm{AH}$ can be confirmed if spontaneous remission occurs or corticos- 
Table 1 Pituitary data - target gland hormone changes in patients before and after treatment

\begin{tabular}{|c|c|c|c|c|c|c|c|c|c|c|c|}
\hline \multirow[b]{2}{*}{ Items } & \multicolumn{4}{|c|}{ Case 1} & \multicolumn{3}{|c|}{ Case 2} & \multicolumn{4}{|c|}{ Case 3} \\
\hline & $\begin{array}{l}\text { At } \\
\text { onset }\end{array}$ & $\begin{array}{l}\text { After } \\
\text { steroid } \\
\text { treatment }\end{array}$ & $\begin{array}{l}\text { At } \\
\text { relapse }\end{array}$ & $\begin{array}{c}\text { After } \\
\text { healing }\end{array}$ & $\begin{array}{l}\text { At } \\
\text { onset }\end{array}$ & $\begin{array}{c}\text { After } \\
\text { remission }\end{array}$ & $\begin{array}{c}\text { At } \\
\text { relapse }\end{array}$ & $\begin{array}{l}\text { At } \\
\text { onset }\end{array}$ & $\begin{array}{l}\text { After } \\
\text { remission }\end{array}$ & $\begin{array}{l}\text { At } \\
\text { relapse }\end{array}$ & $\begin{array}{l}\text { After } \\
\text { healing }\end{array}$ \\
\hline TT3 $(1.01 \sim 2.95$ nmol/L) & 1.9 & 1.78 & 1.45 & 1.58 & 0.76 & 1.32 & 0.88 & 1.72 & 1.95 & 2.76 & 2.93 \\
\hline TT4 (55.3 $160.8 \mathrm{nmol} / \mathrm{L})$ & 86.6 & 95.6 & 101.4 & 89.1 & 34.8 & 56.2 & 65.2 & 101.9 & 75.7 & 144.9 & 113.4 \\
\hline FT3 (2.76-6.30 pmol/L) & 4.65 & 4.67 & 3.98 & 4.44 & 1.71 & 3.38 & 2.55 & 4.34 & 3.54 & 6.08 & 5.81 \\
\hline FT4 (10.4-24.3 pmol/L) & 13.22 & 15.83 & 17.4 & 17.33 & 7.14 & 7.59 & 8.95 & 14.77 & 12.21 & 15.26 & 18.14 \\
\hline TSH (0.35-5.5 mU/L) & 2.81 & 4.77 & 3.21 & 3.27 & 6.14 & 4.77 & 9.14 & 2.42 & 0.5 & 0.35 & 0.8 \\
\hline TGAb $(<60 \mathrm{IU} / \mathrm{mL})$ & 33.9 & - & - & -- & 343.1 & -- & -- & 64 & - & - & -- \\
\hline TPOA $(<60 \mathrm{bIU} / \mathrm{mL})$ & 41.9 & - & - & - & $>1300$ & -- & -- & 60.7 & - & - & - \\
\hline $\begin{array}{l}\text { LH IU/L [Female (adult); 0.5-76.3 } \\
\text { post-menopause: 15.9-54.0] }\end{array}$ & 1.31 & 3.93 & 3.67 & 34.17 & $<0.07$ & $<0.07$ & $<0.07$ & 4.52 & $<0.07$ & 1.89 & 0.5 \\
\hline $\begin{array}{l}\text { FSH IU/L [Female (adult): 1.5-33.4 } \\
\text { post-menopause: 23.0-116.3] }\end{array}$ & 2.85 & 3.0 & 1.94 & 7.68 & 0.48 & 0.3 & 0.49 & 6.16 & 1.49 & 4.28 & 1.81 \\
\hline $\begin{array}{l}\text { E2 pmol/L [Female (adult): 70.0-1938.0 } \\
\text { post-menopause: } \leq 283.7 \text { ] }\end{array}$ & 399.4 & 161.15 & 265.8 & 1509.48 & $<36.7$ & 0.91 & 81.54 & 57.4 & 54.69 & 44.75 & 36.7 \\
\hline $\operatorname{PRL}((2.8 \sim 29.2) \mu \mathrm{g} / \mathrm{L})$ & 26.53 & 12.23 & 40.5 & 22.82 & 45.8 & 54.29 & 54.0 & 26.5 & 16.66 & 23.56 & 18.55 \\
\hline ACTH (normal< $10-12 \mathrm{pmol} / \mathrm{L}$ ) at 8:00 & $<2.2$ & 2.4 & 3.2 & - & $<2.2$ & 7.66 & $<2.2$ & 2.75 & -- & 5.31 & 5.2 \\
\hline ACTH $($ normal $<10-12 \mathrm{pmol} / \mathrm{L}$ ) at 0:00 & $<2.2$ & $<2.2$ & $<2.2$ & - & $<2.2$ & 6.12 & $<2.2$ & 2.51 & -- & 2.36 & $<2.2$ \\
\hline $\mathrm{F}(198.7 \sim 797.5 \mathrm{nmol} / \mathrm{L}) 8: 00$ & 208.5 & 365.1 & 265.9 & - & $<25.7$ & 343.8 & $<25.7$ & 227.8 & --- & 188.9 & 206.4 \\
\hline $\mathrm{F}(0 \sim 105.7 \mathrm{nmol} / \mathrm{L})$ 0:00 & 189.8 & 50.2 & 147.3 & - & $<25.7$ & 202.1 & $<25.7$ & 129.5 & -- & $<25.7$ & $<25.7$ \\
\hline UFC (78.6 $589.6 \mathrm{nmol} / 24 \mathrm{~h})$ & 230.5 & 891.8 & 179.8 & - & $<25.7$ & 327.1 & $<25.7$ & 142.9 & -- & & \\
\hline $\mathrm{GH}(0.06-5.0 \mu \mathrm{g} / \mathrm{L})$ & 0.33 & -- & 0.56 & - & 0.17 & 0.05 & 0.08 & 0.33 & 0.50 & 0.59 & 0.07 \\
\hline
\end{tabular}

TT3, total triiodothyronine; TT4, total thyroxine; FT3, free triiodothyronine; FT4, free thyroxine; TSH, thyrotrophin-stimulating hormone; TGAb, thyroglobulin antibody; TPOA, thyroperoxidase antibody; LH, lutenising hormone; FSH, follicle stimulating hormone; E2, 17- $\beta$ estradiol; PRL, prolactine; ACTH, adrenocorticotropic hormone; F, cortisol; UFC, urinary free cortisol; GH, growth hormone

teroid treatment is effective $[2,3,5]$. Although primary $\mathrm{AH}$ is rare, it has a tendency to recur [2, 3]. However, few studies describe treatment of recurrent autoimmune hypophysitis. Our experience may provide insights to help identify and treat recurrent AH. Herein, we report clinical and treatment data of three recently diagnosed cases of recurrent $\mathrm{AH}$ treated with glucocorticoids plus azathioprine, as previously reported [6].

\section{Patients and Methods}

\section{Case 1}

A 22-year-old female patient was admitted to our hospital on June 17, 2004 due to headache and diplopia. She had sought medical care for similar symptoms at another hospital in January 2004, and "pituitary tumor" was diagnosed based on MRI results.
After resection of the pituitary adenoma at that hospital in February, the patient's headache and diplopia were significantly relieved. Six months later, headache and diplopia recurred along with appearance of left ptosis, hyperprolactinemia, and menstrual disorders. Physical examination showed left ptosis, limited adduction of eyes and bilateral breast milk discharge triggered by palpation. Laboratory test results were ESR $14 \mathrm{~mm} / \mathrm{h}$, high-sensitivity C-reactive protein $1.7 \mathrm{mg} / \mathrm{dL}$, and blood and urine osmolality $287 \mathrm{mOsm} / \mathrm{L}$ and $480 \mathrm{mOsm} / \mathrm{L}$, respectively. Endocrine hormone levels are shown in Table 1. No visual field defects, partial oculomotor nerve paralysis or trochlear nerve palsy was observed. MRI revealed a typical homogenous pituitary enlargement and pituitary stalk thickening as well as abnormal soft tissue signals in the suprasellar cistern, with irregular shape and unclear boundary. Lesions were 
A

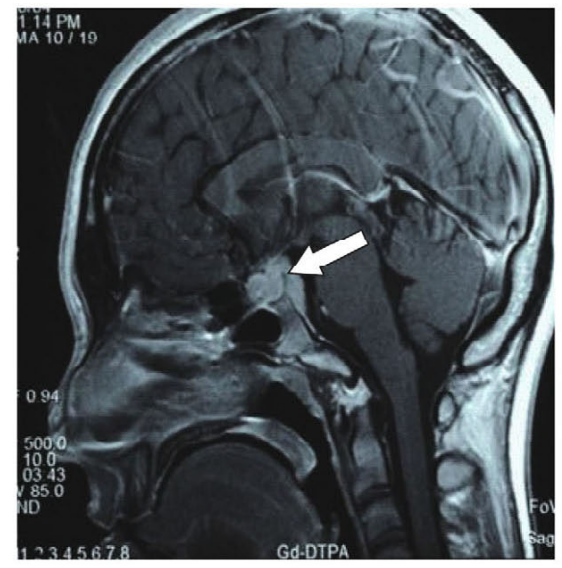

C

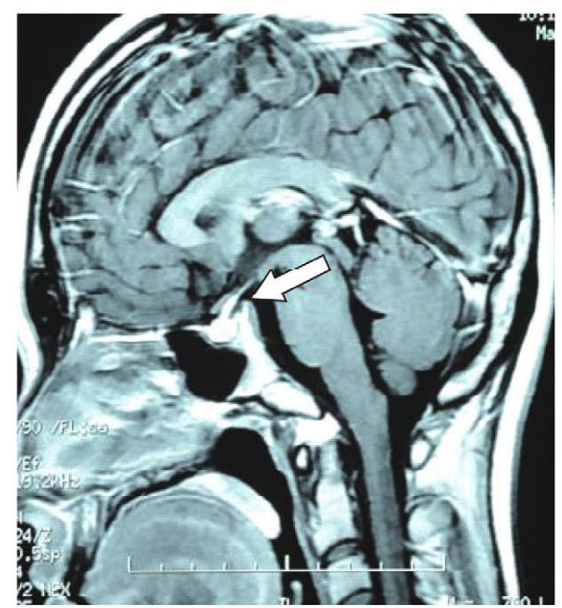

B

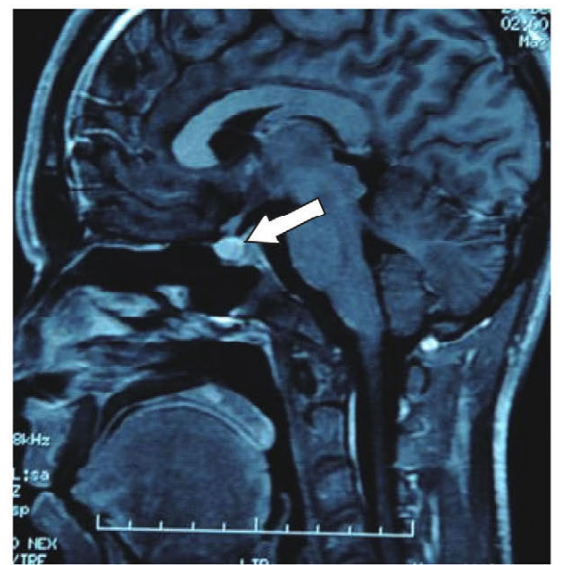

D

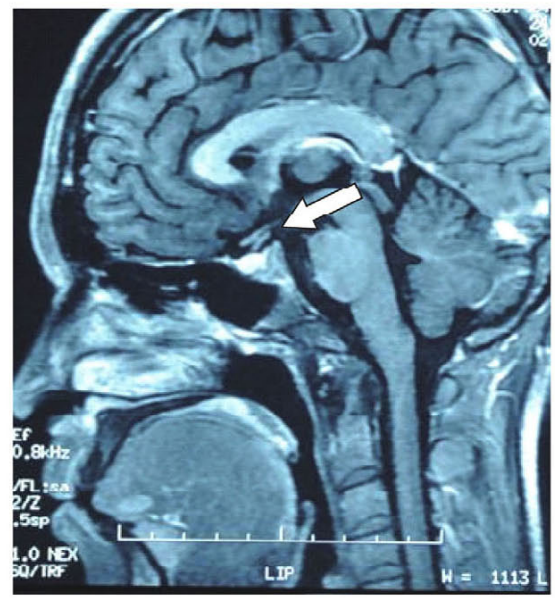

Fig. 1 Preoperative and follow-up MRI of Case 1. A. Preoperative MRI. Homogenous pituitary enlargement is shown, while the pituitary stalk is not shown clearly. Abnormal soft tissue with irregular shape and unclear boundary is observed in the suprasellar cistern, which pushed the optic chiasm upward. Pituitary stalk is not shown clearly. B. MRI after first HDMPT therapy. The pituitary is significantly reduced in size compared to that before surgery. Pituitary stalk is shown clearly. C. MRI after recurrence. Bulging pituitary and thickened pituitary stalk are seen with homogeneous enhancement. D. MRI after treatment for recurrence (Followup at $48^{\text {th }}$ month after admission). Pituitary and pituitary stalk appear normal compared to views in panel C. Signs of disease disappeared.

enhanced significantly after gadolinium, showing the optic chiasm to be pushed upward and wrapping the bilateral internal carotid arteries. The pituitary stalk was not shown clearly (Fig. 1). The Department of Pathology at the Chinese PLA General Hospital reviewed paraffin-embedded sections of pituitary tissue prepared by the hospital where surgery had been performed and found a large amount of lymphocyte infiltration in the pituitary tissue. Autoimmune hypophysitis was diagnosed. High-dose methylprednisolone pulse therapy (HDMPT) was adopted based on that introduced by Kristof et al. [7]. To prevent hormone withdrawal syndrome, a modified HDMPT regimen, consisting of intravenous infusion of $100 \mathrm{mg}$ methylprednisolone daily for 3 days and oral administration of $60 \mathrm{mg}$ prednisone daily for two weeks, was employed by gradually reducing the dosage. The dosage of prednisone was decreased by $5 \mathrm{mg}$ every week after the first two weeks until a $5 \mathrm{mg}$ maintenance dose was reached, which was maintained for 4 weeks. The entire treatment course lasted 16 weeks.

Headache was alleviated on the first day after beginning HDMPT. Diplopia and left ptosis improved significantly after 3 days. MRI showed significant reductions in pituitary size and lesions on the slope of the dorsum sellae and in the cavernous sinus disappeared (Fig. 1). Oral prednisone (2.5 mg /d) was given until the follow-up visit in October 2004 when menstrual 
periods were regular and breast discharge disappeared. Prednisone was withdrawn in November. Headache and diplopia occurred again in December 2005. Pituitary function was assessed, and anterior pituitary function was normal (Table 1). Pituitary function was within normal ranges at onset and relapse. MRI showed bulging pituitary and thickened pituitary stalk with homogeneous enhancement. HDMPT was repeated, and all symptoms disappeared. Prednisone (30 mg/d) and azathioprine (100 mg/d) were administered. Prednisone dosage was gradually reduced by $5 \mathrm{mg}$ after 4 weeks and then by $5 \mathrm{mg}$ weekly until 5 mg maintenace dose was reached, which was maintained for 8 weeks. These drugs were withdrawn after 16 weeks. MRI showed decreased lesion size (Fig. 1). Total follow up was 4 years, and the patient's anterior pituitary function remained normal (data not shown). In August 2008, IGF-1 levels were 237 ng/mL. Repeat MRI indicated no recurrence of disease after treatment at 48 months; the recurrence-free follow-up period was 36 months. At last follow-up, normal pituitary function had resumed.

\section{Case 2}

A 70-year-old female was admitted to our hospital March 20, 2006 presenting with dry mouth, polydipsia and polyuria experienced for one year. She also experienced fatigue, drowsiness, weight loss and loss of pubic and axillary hair. The patient had a history of "hyperthyroidism" and "osteoarthritis." Physical examination revealed blood pressure of $120 / 70 \mathrm{mmHg}$, with dryness of skin and mucous membranes over the entire body. Pubic and axillary hair was thin. Laboratory test results were ESR $32 \mathrm{~mm} / \mathrm{h}$, high-sensitivity C-reactive protein $1.24 \mathrm{mg} / \mathrm{dL}$, blood osmolality $298 \mathrm{mOsm} / \mathrm{L}$, urinary osmolality $168 \mathrm{mOsm} / \mathrm{L}$ and urine specific gravity 1.005. Endocrine hormone levels are shown in Table 1. Anterior pituitary function was decreased at symptom onset and relapse. MRI revealed abnormal signals in the pituitary stalk and hypothalamus, showing homogenous enhancement. Specifically, tongue-like changes were observed above the saddle (hypothalamus). High signals in the posterior pituitary disappeared (data not shown). Autoimmune hypothalamitits was diagnosed. The patient was given prednisone $(60 \mathrm{mg} / \mathrm{d})$, levothyroxine $(100 \mu \mathrm{g} / \mathrm{d})$, and desmopressin acetate $(0.1 \mathrm{mg} / \mathrm{d})$. Symptoms were significantly relieved after 2 weeks. Prednisone dosage was gradually reduced; however, desmopressin treat- ment continued. Prednisone was withdrawn on August $21^{\text {st }}$, and repeat lab test results were urine specific gravity 1.015, blood osmolality $295 \mathrm{mOsm} / \mathrm{L}$ and urine osmolality $341 \mathrm{mOsm} / \mathrm{L}$. Endocrine hormones are shown in Table 1. MRI showed significantly reduced pituitary lesions (Fig. 2). Because secondary diabetes occurred in this patient, multiple subcutaneous injections of insulin were given, and glycemic control was satisfactory. The patient experienced polydipsia, polyuria, cold intolerance, hypohidrosis, and drowsiness. MRI performed in May 2008 showed abnormal oval signals in the hypothalamus with much greater homogeneous enhancement than observed in October 2006. No relapse was observed. Recurrent hypophysitis was considered, and methylprednisolone $(200 \mathrm{mg} / \mathrm{d})$ was given for 3 days followed by $100 \mathrm{mg} /$ day for 3 days. Prednisone $(15 \mathrm{mg} / \mathrm{d})$ plus azathioprine $(100 \mathrm{mg} / \mathrm{d})$ were given for a total of 16 weeks. Levothyroxine, prednisone, and desmopressin acetate replacement therapy was continued. Symptoms were significantly relieved, and repeat MRI showed significantly reduced hypothalamic lesions (Fig. 2); the recurrence-free follow-up period was 6 months. MRI showed no further relapse of disease after treatment at 10 months. Permanent hypopituitarism was present in this patient.

\section{Case 3}

A 32-year-old married female was admitted to our hospital on July 20, 2006 due to polydipsia, polyuria and menstrual disorders with headache and dizziness for the past 8 months. Physical examination revealed slightly dry skin over the entire body. High-sensitivity C-reactive protein was $1.7 \mathrm{mg} / \mathrm{dL}$; blood and urine osmolality were $288 \mathrm{mOsm} / \mathrm{L}$ and $180 \mathrm{mOsm} / \mathrm{L}$, respectively. Endocrine hormone levels are shown in Table 1. MRI revealed "tongue-like" changes; an intrasellar mass with ring-like enhancement and diffuse and enhanced thickening of the pituitary stalk, which was shifted towards the left side. This was similar to a case reported by Honegger et al. [8]. The absence of high signals in the posterior pituitary was also noted (Fig. 3). Autoimmune hypophysitis was diagnosed, and the patient received HDMPT treatment. Cranial MRI showed a thinner pituitary stalk and smaller pituitary 30 days post-treatment. Prednisone $(30 \mathrm{mg} / \mathrm{d})$ was given with gradual reduction of dosage by $5 \mathrm{mg}$ per week after 4 weeks. Polydipsia and polyuria were improved significantly, and menstrual periods became regular. Prednisone dose was reduced to $5 \mathrm{mg} / \mathrm{d}$ on November 
A

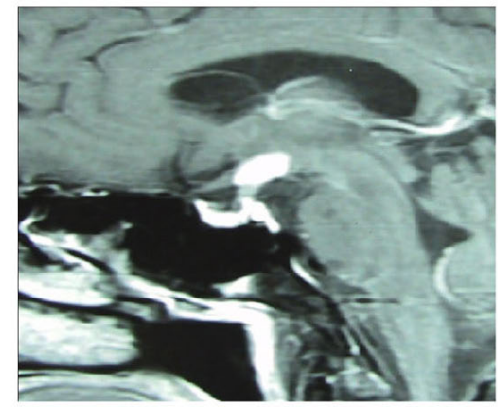

C

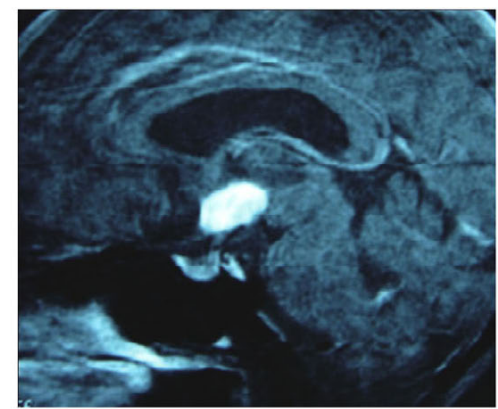

B

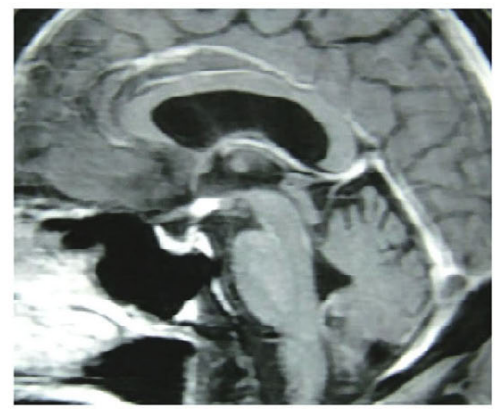

D

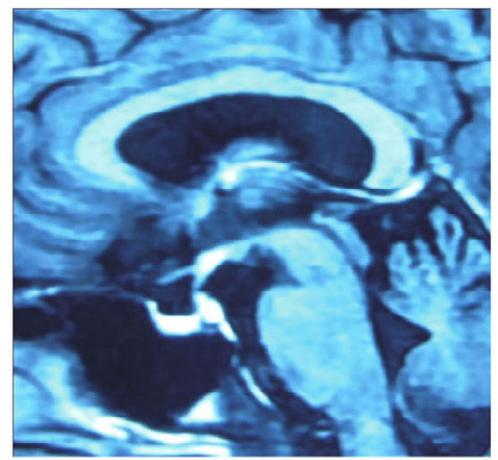

Fig. 2 Pretreatment and follow-up MRI of Case 2. A. Before treatment MRI, showing abnormal, enhanced, and homogeneous signals in the pituitary stalk and hypothalamus. In addition, a tongue-like change above the saddle (hypothalamus), hypothalamitis, was also observed. B. MRI 4 weeks after prednisone therapy. The abnormal signals in pituitary stalk and hypothalamus were significantly reduced. C. MRI after relapse. After the treatment was stopped for 16 months, the abnormal signals in hypothalamus were evenly enhanced. D. After the 16-week treatment regimen with HDMPT plus azathioprine, the lesion almost disappeared.

A

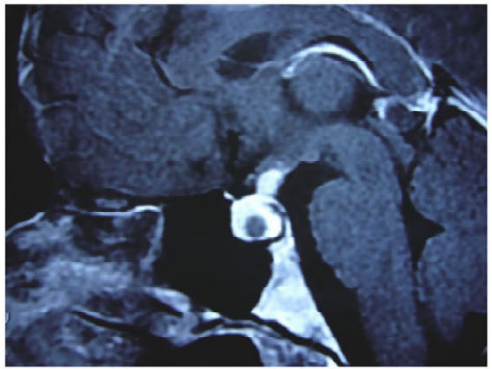

C

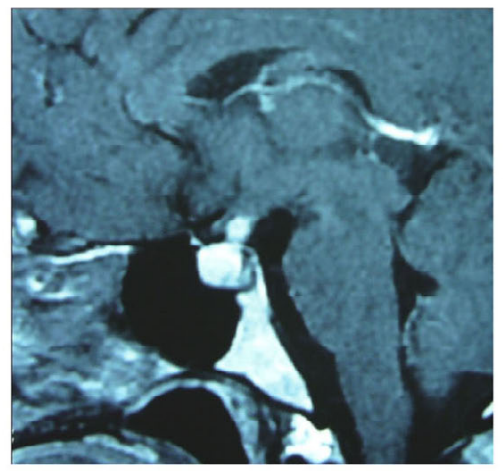

B

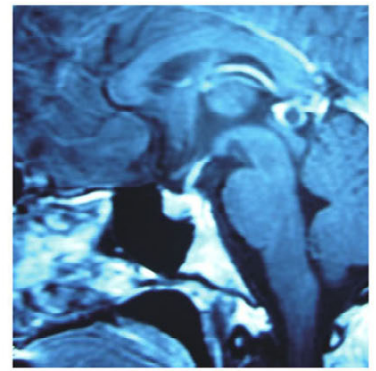

D

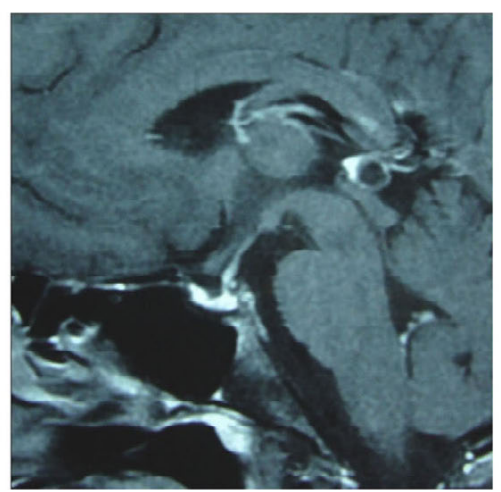

Fig. 3 Pretreatment and follow-up MRI of Case 3. A. Before treatment MRI, showing an enlarged pituitary, an intrasellar mass with ring-like enhancement and diffuse and enhanced thickening of the pituitary stalk with homogeneous enhancement. B. MRI 4 weeks after prednisone therapy. The lesions in pituitary and pituitary stalk were significantly reduced. C. MRI after relapse. The lesion reappeared after the dose of prednisone was reduced. Pituitary and pituitary stalk were enlarged with homogeneously enhanced signals. D. After the 16-week treatment regimen with HDMPT plus azathioprine, the lesions in pituitary and pituitary stalk almost disappeared, and the pituitary was reduced in size. 
9, 2006, and headache and menstrual irregularity were again observed. Urine osmolality was $522 \mathrm{mosm} / \mathrm{L}$ and blood osmolality was $293 \mathrm{mosm} / \mathrm{L}$. Pituitary hormone levels are shown in Table 1. Pituitary functions were within normal ranges at onset and relapse. MRI showed enlarged pituitary and thickening of pituitary stalk with heterogeneous enhancement, thereby relapse was considered (Fig. 3). Prednisone tablets $(30 \mathrm{mg} / \mathrm{d}$, reduced by $5 \mathrm{mg}$ after 4 weeks and by $5 \mathrm{mg}$ weekly thereafter), azathioprine (100 $\mathrm{mg} / \mathrm{d})$, and desmopressin acetate $(0.1 \mathrm{mg} / \mathrm{d})$ were administered. All drugs were withdrawn after 16 weeks. The patient was re-checked in October 2008 and April 2010; her anterior pituitary function was normal, and pituitary lesions were significantly reduced in size (Fig. 3) and stable. In addition, her IGF-1 levels were $178 \mathrm{ng} / \mathrm{mL}$ and $159 \mathrm{ng} / \mathrm{mL}$ in October 2008 and April 2010, respectively. At that follow-up, the patient was not taking medication, and her menstruation was normal; the recurrence-free follow-up period was 18 months. MRI showed no further relapse of disease after treatment at 36 months.

\section{Discussion}

We present clinical and treatment data of three patients with recurrent $\mathrm{AH}$, including a post-menopausal woman with concomitant autoimmune thyroiditis (case 2) and two non-pregnant women (cases 1 and 3). Their clinical manifestations were different: case 1 had headache and diplopia; cases 2 and 3 had diabetes insipidus, and case 2 also had obvious manifestations of anterior pituitary dysfunction. All cases have the typical MRI manifestations of autoimmune hypophysitis [5]. All three patients were treated with glucocorticoids combined with azathioprine, relieving symptoms as early as one day after initiating therapy. Repeat MRI during follow-up revealed significant reduction of lesions and at last follow-up for each patient, 48, 10 and 36 months and the recurrence-free follow-up period was 36,6 , and18 months for cases 1,2 and 3, respectively MRI showed no further recurrence of disease.

$\mathrm{AH}$ is an autoimmune endocrine disease involving lymphocytic infiltration and inflammation of the pituitary. Recent reviews indicate that AH occurs primarily in young women during pregnancy or postpartum $[2,4]$, but it also occurs in postmenopausal women [1], non-pregnant women [9], and men [10, 11, 12]. In the present study, all three cases were female, one of which was postmenopausal. $\mathrm{AH}$ has also been associated with other autoimmune diseases such as Hashimoto's thyroiditis, Addison's disease, Crohn's disease, Wegener's granulomatosis and dacryadenitis $[2,11,13]$. Concomitant autoimmune thyroiditis was observed in case 2.

Since AH occurs only rarely, research is lacking and knowledge of its clinical features or long-term prognosis is insufficient; pathophysiology is largely unknown [3]. AH does not have specific clinical manifestations and, as cases are reviewed, clinical features have become increasingly complex; onset is typically hidden, and clinical manifestations depend on the extent and severity of inflammation [1-3, 7]. It may manifest as symptoms of anterior pituitary dysfunction, including cold intolerance, fatigue, and drowsiness, and may also manifest as diabetes insipidus. If the pituitary enlarges and grows towards the suprasellar region and compresses the optic chiasm, symptoms such as headache, abnormal visual acuity and abnormal visual field may result [4]. The cavernous sinus is sometimes involved, and signs and symptoms of cranial nerve palsy can be present [13]. As an autoimmune disease, the natural course of AH varies. It can relieve spontaneously and recur after effective treatment. Impaired pituitary function can return to normal or decline progressively [14].

Diagnosis of autoimmune hypophysitis is challenging as it is difficult to differentiate from pituitary adenoma, other sellar masses (e.g., germ cell tumors), and other inflammatory diseases (e.g., granuloma) [5]. However, germ cell tumors are usually unresponsive to hormone therapy, and granulomatous and infiltrative diseases, such as sarcoidosis and histiocytosis, generally present more insidiously; therefore, they can be excluded by examining the patient history [5]. A presumptive diagnosis can be made based upon clinical and laboratory findings and MRI; however, a definitive diagnosis requires pathological analysis. In the present study, the first case was diagnosed based upon pathological findings; lymphocyte infiltration was observed in the pituitary using tissue obtained during resection. Diagnoses of cases 2 and 3 were based upon response to treatment. As previously reported, diagnosis of lymphocytic hypophysitis can be confirmed upon spontaneous remission or response to corticosteroid treatment in patients with suspected autoimmune hypophysitis $[2,3,5,7]$. In the absence of a serum marker, response to treatment as a diagnostic marker avoids more invasive diagnostic procedures (i.e., biopsy wit pathologi- 
cal examination). The initial diagnosis of $\mathrm{AH}$ can be given based on clinical manifestations and imaging findings, and the fact that corticosteroid treatment is effective can serve as the main basis for an $\mathrm{AH}$ diagnosis $[5,7]$.

Only several reports of treatment of recurrent $\mathrm{AH}$ are found in the literature [4, 13, 15, 16, 17]. Among these cases, four were young women (aged 26 to 38 years) $[4,13,15,17]$ and one case was a post-menopausal woman (age 53 years) [16]. Recurrence was diagnosed between 12 and 72 months after surgery. Sinha et al. [4] report relapse occurring in a 26-yearold woman during her second pregnancy with spontaneous recovery after delivery. Remission was achieved in the remaining four patients after the second surgery [16], moderate-dose corticosteroid treatment $[13,17]$ and HDMPT [15]. The time of relapse, however, cannot be generalized with limited reports, and no standard treatment protocol is recommended for recurrent AH. Among our patients, relapse occurred twice in case 1 , first at four months postoperatively and again 14 months after HDMPT. In case 2, relapse occurred 16 months after discontinuing moderate-dose prednisone treatment, and relapse occurred in case 3 during dose reduction after effective HDMPT. Close follow-up is essential in recurrent $\mathrm{AH}$, but time or likelihood of relapse cannot be predicted.

Corticosteroid treatment has been an inconsistently effective non-surgical treatment for $\mathrm{AH}$ [13], and relapse is possible even in patients receiving surgical treatment [15]. Some investigators advise avoiding surgery because the natural course of AH may be selflimiting [3, 11]. Kristof et al. introduced HDMPT as treatment for lymphocytic hypophysitis, advocating it as a high-dose, short-term way to administer methylprednisone while minimizing unwanted side effects of chronic corticosteroid therapy [7]. Therapeutic results in nine patients with AH included improved clinical, endocrine, and MRI findings. Another case of AH with gross visual disturbance was successfully treated with HDMPT using a protocol similar to Kristof et al., dramatically reducing visual symptoms on the day after treatment began [18].

Azathioprine-6 also is used for treating $\mathrm{AH}$ with inconsistent results. For example, Lecube et al. reported the first successful treatment of AH with azathioprine after corticosteroids failed, and no clinical or radiological evidence of $\mathrm{AH}$ remained 18 months after treatment [12]. In addition, Papanastasiou et al. reported the successful treatment of primary hypophysitis with azathioprine in two female patients both of which suffered serious side effects from the initial glucocorticoid treatment [19]. However, after an initial transient improvement with methylprednisolone pulse therapy, a 3-month treatment with azathioprine in a male patient with lymphocytic hypophysitis did not restore pituitary function or reduce the pituitary mass [20]. The extensive fibrosis within the pituitary gland as well as the short period of azathioprine treatment may account for the lack of response in the latter case. Although no further relapse has been observed upon azathioprine treatment in the patients reported in this study, we cannot conclude that it prevents relapse. Spontaneous remission of pituitary swelling can occur. Therefore, follow-up is crucial in these patients to rapidly detect relapse and expedite treatment.

Azathioprine, an anti-metabolic agent with immunosuppressive activity, is widely used in immunosuppressive therapy for organ transplant patients and in autoimmune diseases such as rheumatoid arthritis, systemic lupus erythematosis and autoimmune hemolytic anemia. Because positive results have been obtained using azathioprine for other autoimmune diseases and considering the above reports of HDMPT and azathioprine, we adopted a treatment protocol with combined glucocorticoids and azathioprine for treatment of recurrent AH, achieving favorable outcomes. Patients' symptoms were relieved after initial HDMPT, and MRI showed significant reduction in lesion size during follow-up. Normal pituitary function resumed in two patients, and MRI showed no further recurrence of disease in any patient at last follow-up (Table 2). In addition, adverse events associated with azathioprine use, including bone marrow suppression, neutropenia, aplastic anemia, acute pancreatitis, toxic hepatitis, hair loss, mouth ulcers, peritoneal and retinal hemorrhage, pulmonary edema, loss of appetite, nausea, and liver damage, were not observed, which is similar to Lecube et al. [12] and Papanastasiou et al. [19].

In conclusion, our results suggest that glucocorticoids combined with azathioprine constitute effective treatment for recurrent $\mathrm{AH}$. We emphasize the importance of long-term follow-up of AH, including endocrine and radiologic studies. Our data may provide useful information for diagnosis and treatment of recurrent AH. Further investigation with a larger cohort and long-term follow-up is needed to determine whether our treatment method may prevent $\mathrm{AH}$ recurrence. 
Table 2 Summary of three patients with recurrent AH

\begin{tabular}{|c|c|c|c|}
\hline & Case 1 & Case 2 & Case 3 \\
\hline$\overline{\text { Age }}$ & 22 & 70 & 32 \\
\hline Course of disease (month) & 6 & 12 & 8 \\
\hline Clinical manifestations & Headache and diplopia & $\begin{array}{l}\text { Polydipsia and polyuria } \\
\text { accompanied by fatigue and } \\
\text { drowsiness }\end{array}$ & $\begin{array}{l}\text { Polydipsia and polyuria } \\
\text { accompanied by menstrual } \\
\text { disorder }\end{array}$ \\
\hline MRI manifestations & $\begin{array}{l}\text { Abnormal signals in suprasellar } \\
\text { cistern, lesions were enhanced } \\
\text { significantly, pushing the optic } \\
\text { chiasm upward and wrapping } \\
\text { the bilateral internal carotid } \\
\text { arteries, the infundibular stem } \\
\text { was not shown clearly }\end{array}$ & $\begin{array}{l}\text { Abnormal signals in the } \\
\text { infundibular stem and } \\
\text { hypothalamus with homogenous } \\
\text { enhancement, high signals in the } \\
\text { posterior pituitary disappeared }\end{array}$ & $\begin{array}{l}\text { Pituitary was increased in size, } \\
\text { infundibular stem was thickened } \\
\text { significantly and shifted towards } \\
\text { the left side, high signals of the } \\
\text { posterior pituitary disappeared. }\end{array}$ \\
\hline Protocol of the first treatment & Surgery & Moderate-dose prednisone & HDMPT \\
\hline Time of relapse & $\begin{array}{l}\text { First relapse occurred } 4 \text { months } \\
\text { after surgery; second relapse } \\
\text { occurred } 14 \text { months after drug } \\
\text { withdrawal }\end{array}$ & $\begin{array}{l}\text { Sixteen months after withdrawal } \\
\text { of glucocorticoids }\end{array}$ & $\begin{array}{l}\text { During dose reduction process } \\
\text { of glucocorticoids }\end{array}$ \\
\hline Treatment after relapse & HDMPT + azathioprine & HDMPT + azathioprine & Low-dose steroids + azathioprine \\
\hline Duration of treatment after relapse & 16 weeks & 16 weeks & 16 weeks \\
\hline Treatment during follow-up & None & $\begin{array}{l}\text { L-thyroxine } 100 \mathrm{ug} / \text { day } \\
\text { Desmopressin acetate } 0.1 \mathrm{mg} / \text { day } \\
\text { Prednisone } 7.5 \mathrm{mg} / \text { day }\end{array}$ & None \\
\hline Duration of follow-up & 48 months & 10 months & 36 months \\
\hline Outcome & Normal pituitary function & $\begin{array}{l}\text { Anterior pituitary dysfunction; } \\
\text { diabetes insipidus }\end{array}$ & Normal pituitary function \\
\hline
\end{tabular}

\section{References}

1. Jenkins PJ, Chew SL, Lowe DG, Afshart F, Charlesworth M, Besser GM, Wass JA (1995) Lymphocytic hypophysitis: unusual features of a rare disorder. Clin Endocrinol (Oxf) 42: 529-534.

2. Caturegli P, Newschaffer C, Olivi A, Pomper MG, Burger PC, Rose NR (2005) Autoimmune hypophysitis. Endocr Rev 26: 599-614.

3. Abe T, Matsumoto K, Sanno N, Osamura Y (1995) Lymphocytic hypophysitis: Case report. Neurosurgery 36: 1016-1019.

4. Sinha D, Sinha A, Pirie AM (2006) A case of recurrent lymphocytic hypophysitis in pregnancy. J Obstet Gynaecol 26: 255-256.

5. Rivera JA (2006) Lymphocytic hypophysitis: disease spectrum and approach to diagnosis and therapy. Pituitary 9: 35-45.

6. Wang XL, Lu JM, Yang LJ, Lu Z, Dou J, Mu Y, Pan CY (2008) A case of relapsed autoimmune hypothalamitis successfully treated with methylprednisolone and azathioprine. Neuro Endocrinol Lett 29: 874-876.

7. Kristof RA, Van Roost D, Klingmüller D, Springer W, Schramm J (1999) Lymphocytic hypophysitis: noninvasive diagnosis and treatment by high dose methylpred- nisolone pulse therapy? J Neurol Neurosurg Psychiatry 67: 398-402.

8. Honegger J, Fahlbusch R, Bornemann A, Hensen J, Buchfelder M, Muller M, Nomikos P (1997) Lymphocytic and granulomatous hypophysitis: experience with nine cases. Neurosurgery 40: 713-722.

9. Paja M, Estrada J, Ojeda A, Ramon y Cajal S, GarciaUria J, Lucas T (1994) Lymphocytic hypophysitis causing hypopituitaris and diabetes insipidus, and associated with autoimmune thyroiditis, in a non-pregnant woman. Postgrad Med J 70: 220-224.

10. Li J, Ba J, Lv Z, Mu Y, Lu J (2006) Lymphocytic hypophysitis with dacryadenitis. Chin J Endocrinol Metab 22: 574-575 (In Chinese).

11. Lu Z, Li J, Ba J, Yang G, Dou J, Mu Y, Lu J (2009) Lymphocytic hypophysitis with dacryoadenitis in a male patient: non-invasive diagnosis and high-dose methylprednisolone pulse therapy. J Neuro Endocrinol Lett 30: 700-704.

12. Lecube A, Francisco G, Rodriguez D, Ortega A, Codina A, Hernandz C, Simo R (2003) Lymphocytic hypophysitis successfully treated with azathioprine: first case report. J Neurol Neurosurg Psychiatry 74: 1581-1583. 
13. Melgar MA, Mariwalla N, Gloss DS, Walsh JW (2006) Recurrent lymphocytic hypophysitis and bilateral intracavernous carotid artery occlusion. An observation and review of the literature. Neurol Res 28: 177-183.

14. Thodou E, Asa SL, Kontogeorgos G, Kovacs K, Horvath E, Ezzat S (1995) Clinical case seminar: lymphocytic hypophysitis: clinicopathological findings. $J$ Clin Endocrinol Metab 80: 2302-2311.

15. Tsagarakis S, Vassiliadi D, Malagari K, Kontogeorgos G, Thalassinos N (2004) Lymphocytic hypophysitis: late recurrence following successful transsphenoidal surgery. Endocrine 25: 85-90.

16. Nishioka H, Ito H, Fukushima C (1997) Recurrent lymphocytic hypophysitis: case report. Neurosurgery 41: 684-686.

17. Biswas K, Goyal R, Ammini AC, Karak AK, Sarkar C, Mishra NK, Mehta VSl (2005) Recurrent lymphocytic hypophysitis in a woman 27 years after subtotal adrena- lectomy for hypercortisolism possibly of autoimmune origin. J Assoc Physicians India 53: 1066-1069.

18. Yamagami K, Yoshioka K, Sakai H, Fukumoto M, Yamakita T, Hosoi M, Ishii T, Sato T, Tanaka S, Fujii S (2003) Treatment of lymphocytic hypophysitis by highdose methylprednisolone pulse therapy. Intern Med 42: 168-173.

19. Papanastasiou L, Pappa T, Tsiavos V, Tseniklidi E, Androulakis I, Kontogeorgos G, Piaditis G (2011) Azathioprine as an alternative treatment in primary hypophysitis. Pituitary 14: 16-22.

20. Curtò L, Torre ML, Cotta OR, Losa M, Terreni MR, Santarpia L, Trimarchi F, Cannavò S (2010)Lymphocytic hypophysitis: differential diagnosis and effects of highdose pulse steroids, followed by azathioprine, on the pituitary mass and endocrine abnormalities--report of a case and literature review. Scientific World Journal 10: 126-134. 